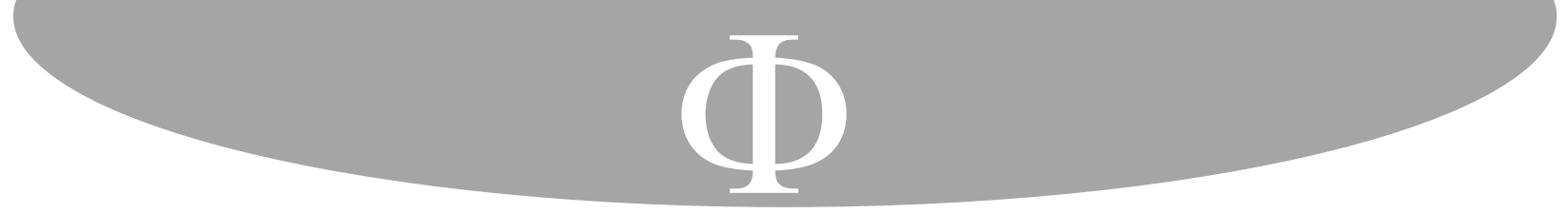

\title{
El quehacer teológico de las mujeres: lugar, método y aportaciones
}

\section{(7) (2)}

Para citar este artículo: Guevara Llaguno, Miren Junkal. «El quehacer teológico de las mujeres: lugar, método y aportaciones». Franciscanum 176, Vol. 63 (2021): 1-29.

\section{Resumen}

El pontificado de Francisco está brindando oportunidades a la reflexión sobre la integración de las mujeres y su visión del mundo y la Iglesia, en el desarrollo de la misión de esta última. Sin embargo, el binomio mujer y teología no significa siempre y en todo lugar lo mismo, y es bueno exponerlo con claridad para no crear equívocos. La oportunidad del momento eclesial permite exponer los logros de las mujeres que en el servicio de la teología llevan muchos años pensando sobre lo específico de su aportación en lo relativo al método teológico; al lugar desde el que se hace la teología; y al particular aporte en el estudio de los tratados teológicos.

\section{Palabras clave}

Mujeres teólogas, teología con rostro de mujer, teología de la mujer, método teológico, quehacer teológico.

\section{The theological work of women: place, method and contributions}

\begin{abstract}
The pontificate of Francisco is providing opportunities for reflection on the integration of women and their vision of the world and the Church, in the development of its mission. However, the binomial woman and theology does not always and everywhere mean the same, and it is good to present it clearly so as not to create ambiguities. The opportunity of the ecclesial moment allows presenting the achievements of women who in the service of theology have been thinking for many years about the specificity of their contribution in relation to the theological method to the place from which theology is made and to the particular contribution in the study of the theological treatises.
\end{abstract}

\footnotetext{
* Licenciada en Derecho, Universidad Pontificia Comillas (Madrid); Doctora en Teología. Facultad de Teología de Granada (España). Catedrático del departamento de Sagrada Escritura en Facultad de Teología de Granada (España). ORCID: https://orcid.org/0000-0003-1097-1858. Contacto: junkalguevara@yahoo.es.
} 


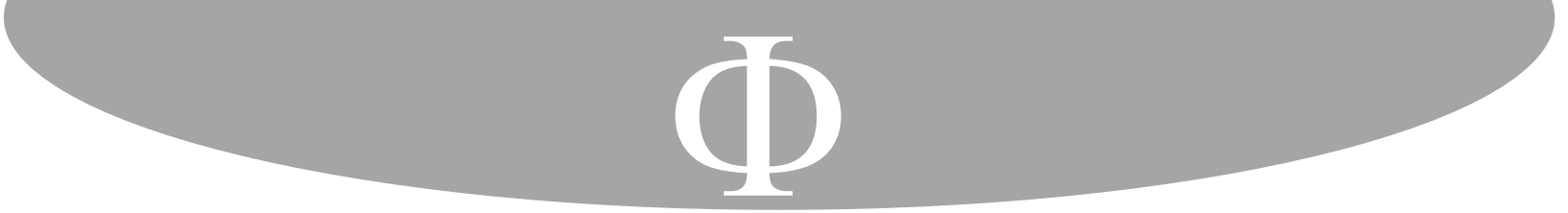

\section{Keywords}

Women theologians, Women's Perspective in Theology, Theology about women, The theological method, The theological work.

\section{Introducción}

¿No basta Señor, que nos tiene el mundo acorraladas e incapaces para que no hagamos cosa que valga nada por Vos en público ni osemos hablar algunas verdades que lloramos en secreto, sino que no nos habíais de oír petición tan justa? No lo creo yo, Señor, de vuestra bondad y justicia, que sois justo juez y no como los jueces del mundo que, como son hijos de Adán y, en fin, todos varones, no hay virtud de mujer que no tengan por sospechosa ${ }^{1}$.

En el s. XVI, cuando se discutía en el seno de la Iglesia si la mujer podía ser sujeto de oración, Teresa de Jesús decidió narrar la irrupción de Dios en su vida creando una Teología narrativa que no era sino el fruto de haber convertido su vida en Teología; "y no cualquier Teología, pues la suya no fue una Teología especulativa, académica y de lógica sino una Teología que nace de una revelación» ${ }^{2}$.

Encontré estos textos cuando revisaba este trabajo y creí reconocer en él las inquietudes de muchas de las teólogas que escribían sobre este binomio «mujer y Teología», y que, de una u otra forma, ponían de manifiesto la dificultad de ser mujer en la Iglesia, y la dificultad aún mayor de dedicarse a la Teología académica: dificultad para acceder a los estudios superiores; para afrontar con resiliencia los juicios sobre nuestras pretensiones de poder; para mostrar la capacidad intelectual necesaria; para defender una nueva epistemología...

Por otra parte, consideré la necesidad de reflexionar y explorar la existencia de una singular aportación a la Teología en el modo de abordar este oficio las mujeres.

Además, pensé que este era un momento eclesial oportuno para detenerse a pensar sobre este binomio Teología-mujer. El pontificado de Francisco, casi desde su inauguración, tiene a la mujer en el punto de su reflexión pastoral y de sus decisiones de gobierno. No en vano cuatro meses después de ser elegido papa, en el viaje de regreso de la Jornada mundial de la juventud de Brasil, respondiendo a una pregunta a propósito del diaconado femenino y la presencia de la mujer en los dicasterios romanos, afirmó: «Creo que nosotros no hemos hecho todavía una Teología profunda de la mujer en la Iglesia»³.

\footnotetext{
${ }^{1}$ Teresa de Jesús, «Camino de perfección», en Obras completas (Burgos: Monte Carmelo, 1998), 435.

${ }^{2}$ María Elena Garmendia, Porque soy hija de Abrahán. Sacerdocio femenino ¿un clamor del Espíritu? (Bilbao: Desclée De Brouwer, 2017).

${ }^{3}$ Viaje Apostólico a Río de Janeiro con ocasión de la XXVIII Jornada Mundial de la juventud; Conferencia de prensa del Santo Padre Francisco durante el vuelo de regreso a Roma, Domingo 28 De Julio De 2013; en línea, http://www.vatican.va/content/francesco/es/speeches/2013/july/documents/papa-francesco_20130728_gmgconferenza-stampa.html, consultada en diciembre 3, 2019.
} 


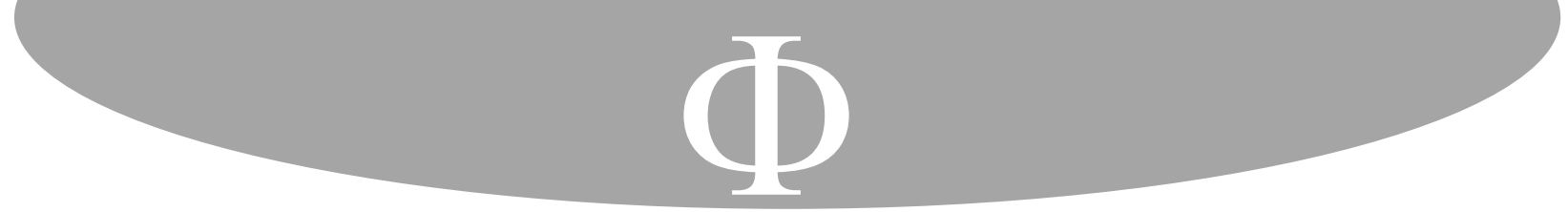

Así que, en este artículo, no me detendré en las dificultades que tantas veces son las mismas que acusó Teresa de Jesús, sino en el examen y la consideración de los logros y aportes peculiares que la perspectiva de las mujeres teólogas ofrece al método teológico y a los distintos tratados. No resulta fácil la tarea, no sólo porque el quehacer teológico de las mujeres ha alcanzado un volumen y una madurez notable, sino porque reflexionar sobre la peculiar aportación de las mujeres (o de los hombres) corre el riesgo de verse contaminado por las imágenes, tareas etc., que vienen determinados por los roles o estereotipos de género propios de la sociedad en la que desempeño mi tarea. Y desvelar la impronta de los estereotipos de género también constituye un desafío personal en un tiempo en que la categoría de género se ha introducido en el discurso teológico de modo consciente y crítico.

El lector podrá notar que prácticamente he seguido esta cuestión a partir del trabajo de las autoras latinoamericanas y españolas; creo que la riqueza de las búsquedas de esas teólogas y el bagaje de todas ellas me permite articular suficientemente bien las ideas que quiero transmitir; por otra parte, eso me ayuda a ofrecer al lector una bibliografía en lengua castellana que le permita seguir profundizando en los temas que aquí se expongan.

\section{Delimitando el campo de trabajo}

Desde finales del s. XIX y, sobre todo, en el s. XX, el pensamiento en torno a la mujer fue tomando fuerza y alentando un movimiento universal de reflexión y reivindicación de la dignidad y los derechos de las mujeres. Este movimiento que de hecho se había ido manifestando desde la revolución francesa, con todas sus formas y versiones, ha constituido una fuerza para reclamar la presencia y el protagonismo de las mujeres en todos los ámbitos de la sociedad, también al interior de las Iglesias.

Como hace notar V. Azcuy «el surgimiento de mujeres que hacen Teología (...) va generando, paulatinamente, una toma de conciencia acerca de esta realidad y su novedad en el ámbito teológico y eclesial tanto en varones como en mujeres» ${ }^{4}$.

Los estudios que hacen balance de la incorporación de las mujeres al oficio de la Teología al menos en los últimos cincuenta años muestran cómo en el mundo de lengua hispana es posible hablar ya de una segunda generación de teólogas que no sólo presenta un perfil formativo mucho más sólido sino que, además, revela una mayor especialización y una pluralidad de posiciones enormemente interesante ${ }^{5}$.

Como mujer dedicada a la Teología de forma profesional y miembro de esa «segunda» generación, necesito reflexionar sobre lo que aporta y enriquece a la Teología el

\footnotetext{
${ }^{4}$ Virginia Raquel Azcuy, «El lugar teológico de las mujeres», Proyecto 37 (2001): 11-34.

5 Dolores Aleixandre, «Mujeres en la Iglesia: memoria de una etapa, proyecto de un futuro», Almogarén 17 (1995): 179-191. Silvia Martínez Cano, «40 años de Teología Feminista en España», Carthaginensia: Revista de estudios e investigación 66 (2018): 449-474.
} 


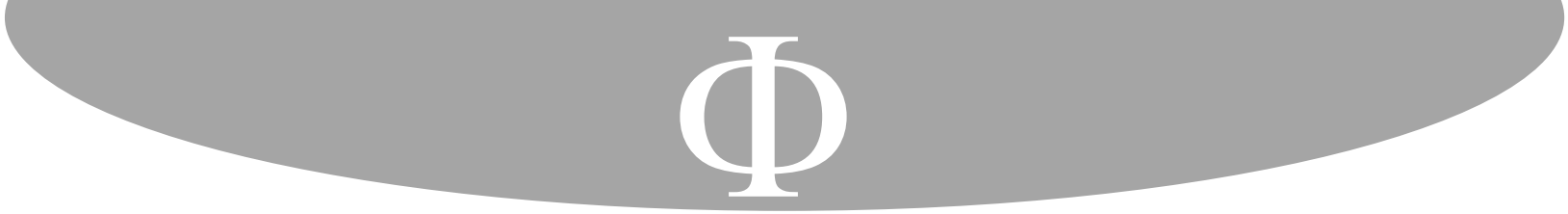

hecho de ser mujer; cuál parece ser la contribución de las mujeres al quehacer teológico entrado ya el s. XXI.

La necesidad de reflexionar tiene que ver con algo que una de las mujeres decanas en el oficio de la Teología en España, la biblista D. Aleixandre, formuló en una entrevista, y es que durante casi veinte siglos se ha hablado de Dios con un único altavoz, mientras que la incorporación progresiva de las mujeres al quehacer teológico ha permitido que esa voz se escuchara en estéreo ${ }^{6}$.

¿Hay elementos singulares en el quehacer teológico de las mujeres?

Siguiendo la metáfora: ¿De qué forma ha mejorado el sonido de la Teología? ¿Qué matices y ritmos nuevos o desconocidos se escuchan en la sinfonía de la Teología?

En realidad, son preguntas que las mujeres teólogas se vienen haciendo hace tiempo ${ }^{7}$, porque puedo sospechar que, más allá de la impronta de los roles de género o incluso contando con ellos, hay un sonido propio desvelado en la sinfonía de la Teología gracias a la aportación de las mujeres porque su tarea teológica es «un logos pronunciado desde la vida y la praxis histórico-eclesial de las mujeres» ${ }^{8}$.

No sólo eso. Es una pregunta que también se hacen algunos hombres dedicados a la Teología: «Cada uno como teólogo debe preguntarse si reconoce ese aporte nuevo de las mujeres teólogas, si los incorpora en su propia reflexión. Porque fácilmente puede suceder que los dejemos de lado como "cosas de mujeres", respetables en su propio ámbito, pero sin mayor proyección universal»?.

Personalmente, como teóloga, me sitúo en el entorno de lo que algunos han llamado «Teología con rostro de mujer» ${ }^{10} \mathrm{o}$ «Teología en perspectiva de mujer» ${ }^{11}$, y que identifica la perspectiva de las mujeres teólogas que quieren subrayar el acento que cualifica la óptica de quien hace Teología siendo mujer:

En mi quehacer teológico siempre tomo más conciencia de que mi experiencia de mujer, o mejor, la manera como Dios crea y recrea incesantemente la mujer que yo soy, imprime

\footnotetext{
6 «María Dolores Aleixandre, teóloga: hasta ahora, se nos ha estado hablando de Dios con un solo altavoz», Diario de Córdoba, 17 de noviembre de 2007, consultada en junio 1, 2020, https://www.diariocordoba.com/cordoba-ciudad/2007/11/17/maria-dolores-aleixandre-teologa-ahora38355432.html.

${ }^{7}$ María Clara Luchetti Bingemer, «La mujer teóloga: vocación y ministerio», Christus 720 (2000): 48-49.

${ }^{8}$ Virginia Raquel Azcuy, «El lugar teológico de las mujeres»: 16.

${ }^{9}$ Sergio Silva, «La Exhortación Apostólica del papa Francisco como desafío a los teólogos», Teología y vida 3 (2014): 549-569.

${ }^{10}$ «Teología con rostro de mujer» es el título que Alternativas, una revista de análisis y reflexión teológica dio a su monográfico16/17, Vol. 7 (2000).

${ }^{11}$ María Teresa Porcile, Con ojos de mujer. Lo femenino en la teología y en la espiritualidad (Buenos Aires: Editorial Claretiana, 2000).
} 


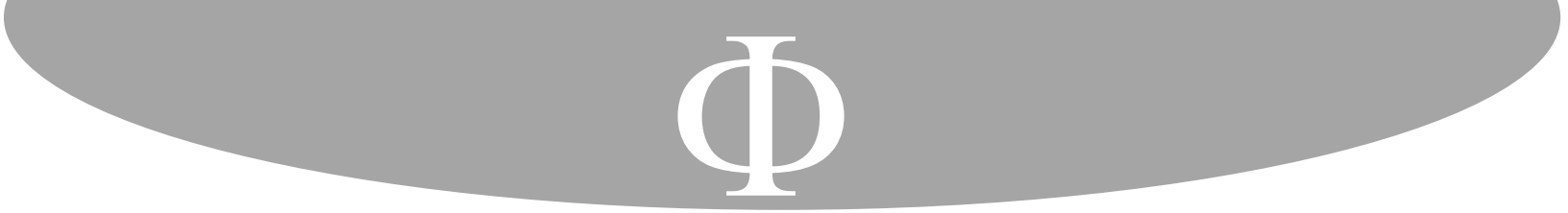

una marca diferente en mi reflexión y en mi discurso. Asumir esa marca, tiene su mezcla de pasión y gloria, pero es un dato del cual no se puede escapar porque es de nivel ontológico $^{12 .}$

Quiero pensar desde la perspectiva de quien trata de estar comprometida con las mujeres que buscan verse representadas en la Teología no como objetos de la misma, sino como sujetos y como tales capaces de hacer una Teología que parta de la experiencia de las mujeres y de su cosmovisión, diferente de la de los hombres por distintas razones, diferente pero equivalente.

No me identifico como teóloga feminista, al menos en los términos en los que ha sido definida con cierta autoridad ${ }^{13}$, y en sus procedimientos metodológicos y hermenéuticos ${ }^{14}$, pero sí reconozco el feminismo como «aguijón para la Teología» (V. Azcuy), ${ }^{y}$ creo que las mujeres que hacemos Teología hoy debemos reconocer la importancia que el movimiento teológico feminista ha tenido en la reflexión en torno al binomio «mujer y Teología» 15 .

No sólo eso; como ya dije, en este trabajo beberé de las reflexiones de muchas teólogas alineadas en el feminismo en cualquiera de sus expresiones, porque me parece que aportan un pensamiento en muchos casos maduro y muy bien articulado; denotan una sensibilidad para con la injusticia de cualquier tipo que nos ayuda a discernir; e intuyen unas líneas de futuro que teólogos y teólogas no debemos ignorar.

\section{Pensando los rasgos propios de la epistemología de una Teología de autoría femenina 2.1 El auditus temporis o el lugar de la Teología ${ }^{16}$}

Si toda elaboración teológica trata de conseguir la integración del mensaje revelado o auditus fidei y su actualización en el presente, el auditus temporis, de manera que «insiste en la unidad de la verdad y por tanto en la unidad fundamental de la Teología en sí misma» ${ }^{17,}$ entonces, cualquier Teología hecha por mujeres debe aceptar el mismo desafío

\footnotetext{
${ }^{12}$ María Clara Luchetti Bingemer, «Teología saboreando las razones de mi fe», en Juan José Tamayo y Juan Bosch, Panorama de la Teología latinoamericana: cuando vida y pensamiento son inseparables (Estella: Verbo Divino, 2001).

${ }^{13}$ Catharina Halkes, «Teología Feminista. Balance Provisional», Concilium 154 (1980): 122-137.

${ }^{14}$ Olga Consuelo Vélez, «Teología de la mujer, feminismo y género», Theologica Xaveriana 140 (2001): $545-$ 564.

${ }^{15}$ Virginia Raquel Azcuy, «El lugar teológico de las mujeres»: 15.

${ }^{16}$ Puede ayudar la reflexión epistemológica en torno a la Teología de la Liberación de Juan Carlos Scannone, «Cuestiones actuales de epistemología teológica. Apuntes de la Teología de la liberación», Stromata 45 (1990): 293-336; además, Gonzalo J. Zarazaga, «La religiosidad popular latinoamericana como "lugar teológico"», Stromata 55 (1999): 3-18; Marta López Alonso, "Mujer y bioética teológica. "Vino nuevo en odres nuevos" (Mt 9,17)», en Francisco Javier De la Torr, ed., Mujer, mujeres y bioética (Madrid: Universidad Pontificia Comillas, 2010), 193-198.

${ }^{17}$ Comisión Teológica Internacional, La teología hoy: perspectivas, principios y criterios. 29 de noviembre de 2011, consultada en diciembre $17, \quad 2019$, http://www.vatican.va/roman_curia/congregations/cfaith/cti_documents/rc_cti_doc_20111129_teologiaoggi_sp.html.
} 


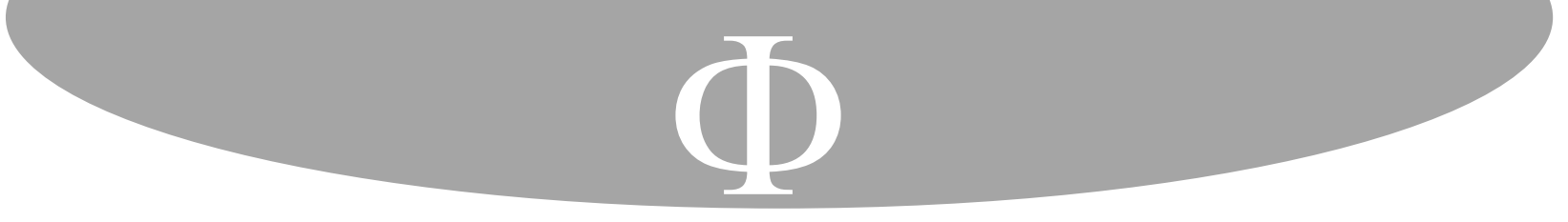

Parece, pues, que podemos referirnos a las mujeres como un sujeto teológico emergente que ofrece una inteligencia de la fe desde la perspectiva de las mujeres, y que, además, impulsa una hermenéutica teológica con tintes de novedad.

\subsection{Los rasgos propios del lugar del auditus fidei de la Teología en perspectiva de mujer}

Quizás antes de profundizar en los rasgos propios, podríamos detenernos un momento en algo que apuntamos más arriba a propósito de los lugares por los que se cuela la Teología hecha por mujeres ${ }^{23}$, y que tiene, a mi modo de ver, mucho interés a la hora de hablar de la Teología de las mujeres.

Influenciadas por la perspectiva masculina a la hora de comprender la Teología, también las mujeres tenemos el riesgo de identificar «Teología» con Teología «académica», y reducir esta al magisterio teológico que desempeñan algunas mujeres que se dedican profesionalmente a la Teología.

Sin embargo, en una investigación sobre Teología feminista en América Latina de L. Fernández, me pareció enormemente reveladora la consideración de la categoría «quehacer teológico» para ampliar el escenario en el que es posible encontrar a las mujeres haciendo Teología:

Hemos optado por hablar de "quehacer teológico" más que de Teología, puesto que en cuanto disciplina y en un sentido tradicional, esta se asocia casi exclusivamente a los ámbitos académicos, desarrollados por profesionales que acreditan su experticia con determinados grados. Sin embargo, los condicionamientos que excluyen a las mujeres de dichos espacios son de tal magnitud en la Teología, que nos parece importante validar las nuevas geografías que las mujeres han buscado para sí y sus discursos de lo sagrado y por lo tanto entenderemos en esta categoría el proceso de empoderamiento que han hecho mujeres, de diversos contextos, al significar o resignificar sus propias experiencias y prácticas de fe, ya sea que las hayan sistematizado discursivamente o no, en los centros tradicionales de estudio o fuera de ellos, incluyendo como lugares teológicos los espacios pastorales, es decir, aquellos lugares al interior de la iglesia católica, como grupos diocesanos, parroquiales, de comunidades religiosas, y donde las mujeres teniendo posturas más o menos criticas, siguen adhiriendo a la confesionalidad desde la pertenencia estructural a la iglesia católico romana y grupos independientes, donde mujeres en solitario o en colectivos, reconociéndose originalmente de tradición católica, hoy hacen sus búsquedas de manera autónoma y sin ninguna regulación eclesial ${ }^{24}$.

Porque, si es verdad que la liturgia y la catequesis son espacios privilegiados para la interpretación de la Escritura, y para la formación teológica de los fieles, entonces la propia geografía de la misión de la Iglesia en la que han actuado tradicionalmente las mujeres nos

\footnotetext{
${ }^{23}$ Ivone Gebara, «La mujer hace Teología. Un ensayo para la reflexión», in El rostro femenino de la Teología, ed. Elsa Tamez, María Clara Luchetti Bingemer y Tereza Cavalcanti (San José: Departamento Ecuménico de Investigación, 1988), 13-15.

${ }^{24}$ Loreto Fernández, «Mujeres haciendo teología. Redescubriendo las teologías feministas en América Latina», Analecta 3, Vol. 3 (2009): 65-73.
} 


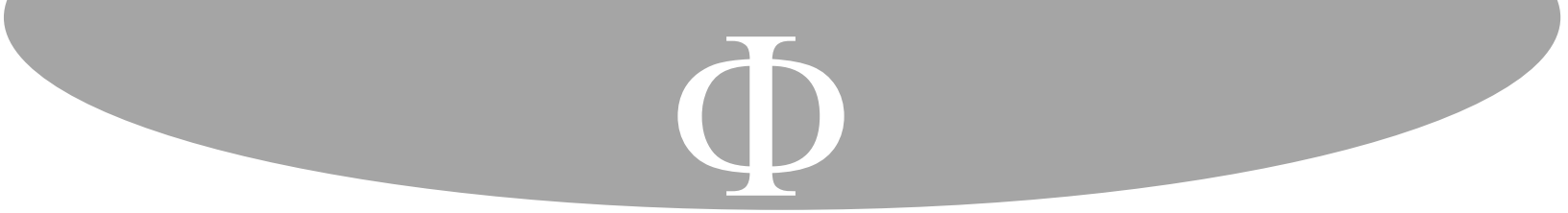

extender la verdad enseñada por la autoridad de Magisterio, a exponerla, a justificarla y a defenderla» ${ }^{35}$.

Como hizo notar la Comisión Teológica Internacional, en el mundo teológico contemporáneo se ha ido imponiendo poco a poco la necesidad de hablar de una pluralidad de Teologías ${ }^{36 .}$

La pregunta que nos hacemos en este momento es si existen diferencias o singularidaes en las metodologías teológicas entre los trabajos de mujeres y varones.

El primer elemento que parece marcar una diferencia, y en cierta manera un desafío al método teológico en su rigor y sistematicidad es el papel que el concepto y la razón protagonizan en la Teología que hacen las mujeres.

Algunas mujeres tratan de llamar la atención sobre el hecho de que el conocimiento teológico no es algo que se comunique primaria y únicamente a través de la razón y el concepto. Así, F. Elizondo, afirma que el modo de hacer Teología de las mujeres ensancha la racionalidad para que incluya la experiencia ${ }^{37}$ y esa experiencia no levanta la racionalidad como bandera única del quehacer teológico. Y C. Costa considera que:

En comparación con la mentalidad masculina, las mujeres, tal vez comprenden mejor la utilidad de conjugar entornos especulativos lejanos y distantes que están mucho más ligados de lo que parecen. El mundo intelectual femenino podría reforzar el intercambio entre la pluralidad del conocimiento, para dar más espacio a la muldisciplinariedad, a la transdisciplinariedad, a la «fermentación de todo conocimiento» (Francisco) ${ }^{38}$.

Sin embargo, también se oyen voces que creen que estas afirmaciones necesitan ser tomadas, todavía hoy, con cierta prudencia. En opinión de Yvonne Dohna Schlobitten:

No está tan claro que nuestro "sentir intelectual" de las mujeres, sea un método, una forma científica de proceder que puede ser verificada, definida y así entrar en la enseñanza de las diferentes universidades. Es difícil definir un "criterio femenino" o "sentidos espirituales femeninos". Si nos reunimos regularmente, conociendo la forma de pensar de los demás, es posible llegar a una mejor definición de nuestro camino ${ }^{39}$.

\footnotetext{
35 Comisión Teológica Internacional, Magisterio y Teología, 1975, consultada en diciembre 17, 2019, http://www.vatican.va/roman_curia/congregations/cfaith/cti_documents/rc_cti_1975_magisteroteologia_sp.html.

${ }^{36}$ Comisión Teológica Internacional, La Teología hoy: perspectivas, principios y criterios.

${ }^{37}$ Felisa Elizondo, «Mujer», en Mercedes Navarro, ed., 10 mujeres escriben Teología (Estella: Verbo Divino, 2004), 204.

${ }^{38}$ Silvia Guidi, «La voz de las mujeres», Donne Chiesa Mondo 47 (2019): 5.

${ }^{39}$ Silvia Guidi, «La voz de las mujeres»: 4.
} 


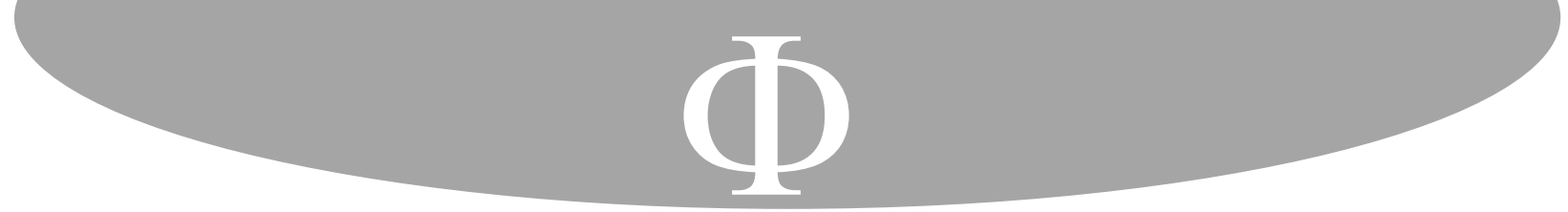

Así, esta contribución que ha llegado principalmente de las mujeres tiene que ser tomada con atención porque puede tener sus riesgos. Puede ser interesante recordar el diálogo entre H. Hassmann y E. Támez en 1986:

ELSA: Varias mujeres en América Latina nos hemos venido dando cuenta de que el camino lógico, racional, es no sólo el único camino, para hacer Teología; hay otras formas.

HUGO: Lo que dices es muy importante, y creo que por allí hay una contribución que quizás sólo la mujer puede dar, pero, ojo a la trampa, si los varones teólogos llegaran a admitir diciendo: "bueno hay distintas maneras de hacer Teología, hay lenguajes más racionales, lenguajes más poéticos, dejemos a la mujer sus lenguajes más poéticos, y nosotros sigamos con los racionales", no hay que caer en esa trampa. Todos, hombres y mujeres, debemos saber que hay diversos lenguajes, diversas formas de conocimiento y de comunicación

Creo que la mujer da una contribución muy fuerte ahí, pero si ella dijera ¡esta es nuestra contribución! caeríamos en una trampa, porque yo creo en la inteligencia racional de la mujer en la misma forma como el hombre la puede tener. Creo que es un problema general que atañe a teólogos y a teólogas.

ELSA: Tiene que ver con nuestra cultura occidentalizada. . .

HUGO: ... . donde creemos que la única manera de conocer es la manera lógico-racional, donde yo pienso incluso que las formas más perfectas del conocimiento no son esas ${ }^{40}$.

Por otra parte, las mujeres cuando hacemos Teología tendemos a incluir la experiencia vital, configurando el discurso teológico con una coloración práctico-narrativo bastante original. En ese sentido, creo que se puede decir que ha sido gracias a las mujeres que se ha ido introduciendo en el quehacer teológico de la Iglesia una llamada a que cabeza, corazón y entrañas se unan en el discurso teológico.

Existen dos maneras fundamentales de expresarse: separándose de las palabras, jugando con ellas como si fueran piezas de una construcción o dejándolas subir del fondo de las propias entrañas, como una prolongación de uno mismo.

La expresión femenina está mucho más cerca de este segundo modo y la gracia y la novedad de nuestra aportación al mundo teológico va a estar en relación con un nuevo lenguaje que sea comprensible también para los no iniciados porque ha sido elaborado en contacto con la vida y llega grávido de experiencia sentida ${ }^{41}$.

\footnotetext{
${ }^{40}$ Elsa Tamez, Teólogos de la liberación hablan sobre la mujer (San José: Editorial Departamento Ecuménico de Investigaciones, 1986).

${ }^{41}$ Dolores Aleixandre, «Mujeres en la Iglesia: memoria de una etapa, proyecto de un futuro»: 185.
} 


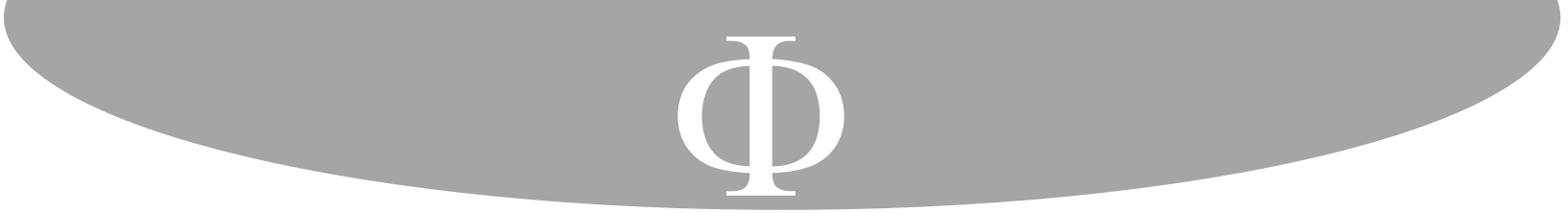

Así, parece que existe acuerdo en afirmar que las mujeres que hacemos Teología tendemos a utilizar un lenguaje menos abstracto; más inclusivo y universal, y de perspectiva

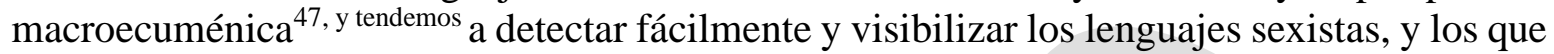
tienen un tinte violento (racista, colonial, opresor), así como los lenguajes exclusivamente eurocéntricos ${ }^{48}$.

No sólo eso; parece que la dimensión testimonial forma parte de la forma de hacer Teología las mujeres, y, si atendemos a las afirmaciones de T. Porcile, existe una conexión entre el martirio, como máxima mostración de la fe, y el modo de hacer Teología las mujeres: «El verdadero ser de la fe, de la misión y de la Teología como anuncio de la Buena Nueva, tiene que ver con el martirio. Lo que el mártir hace extraordinariamente, por la fuerza del Espíritu, la mujer lo tiene inscrito en su cuerpo como parte constitutiva de su ser mismo: todo nacimiento lleva sangre ${ }^{49}$.

Así, en conjunto, la Teología hecha por mujeres no se contenta con una inteligencia abstracta de los enunciados escriturísticos o dogmáticos; es menos apologética; utiliza un nuevo lenguaje teológico, hace de la experiencia cotidiana una fuente de reflexión, y conduce a la aplicación pastoral de sus enunciados.

\section{El acento propio de las mujeres en la reflexión de los contenidos teológicos 3.1 La Biblia}

La Biblia es, posiblemente, la ocupación a la que se dedican más mujeres teólogas. De hecho, las mujeres relacionadas con los estudios bíblicos han sido capaces de publicar, por ejemplo, una colección de 22 volúmenes, «La Biblia y las mujeres» ${ }^{50}$, sobre la historia de la recepción de la Biblia y su influencia en Occidente. En el proyecto colaboran más de 400 autoras, y los textos, traducidos a cuatro lenguas, se publican simultáneamente en Alemania, España, Bélgica, Estados Unidos e Italia.

Dado que la revelación de Dios se produce en la historia, y se transmite en textos escritos en el pasado pero que contienen palabra de Dios para nosotros hoy, no extraña que las mujeres biblistas traten, como dice E. Támez, «de descubrir sentidos nuevos al texto, que digan su palabra a la realidad inmediata que la reclama» 51.

\footnotetext{
http://www.vatican.va/content/francesco/es/speeches/2019/june/documents/papafrancesco_20190621_teologia-napoli.html.

${ }^{47}$ María Teresa Porcile, «Cristología en femenino», Diakonia 110 (2004): 80-97.

${ }^{48}$ Felisa Elizondo, «Mujer», 205-206.

${ }^{49}$ Maria Teresa Porcile, La mujer, espacio de salvación: misión de la mujer en la Iglesia, una perspectiva antropológica, 359.

${ }^{50}$ La Biblia y las Mujeres. Colección de exégesis, cultura e historia, consultada en septiembre 19, 2019, http://www.bibleandwomen.org/ES/.

${ }^{51}$ Elsa Támez, «Descubriendo rostros distintos de Dios», Redes Cristianas, consultada en septiembre 15, 2020, http://www.redcristianaradical.org/uploads/3/4/5/3/34530228/descubriendo_rostros_distintos_de_dios_e_tam ez.pdf.
} 


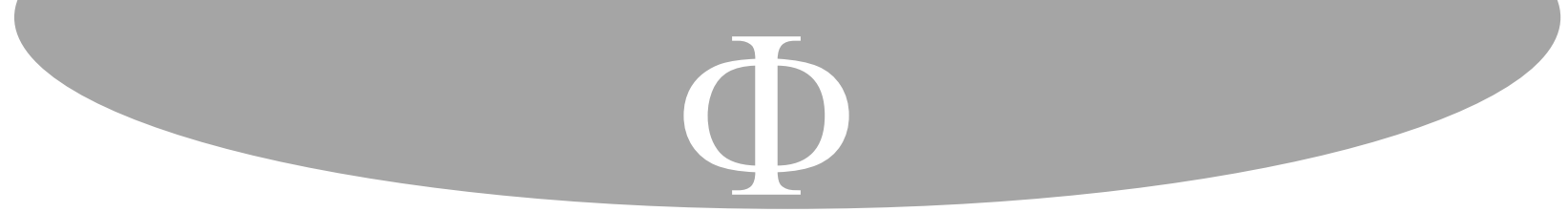

Así, no es infrecuente que la exégesis de mujeres desvele e identifique la experiencia de lo sagrado que las personas tienen en su vida cotidiana; de esta forma, el análisis histórico crítico, más preocupado del pasado del texto (su origen, autoría, contexto), y de su carácter literario (género literario, uso del lenguaje, estructuras formales) ${ }^{52}$, se ve enriquecido por la incorporación de preguntas directamente relacionadas con cuestiones de carácter social.

Estas preguntas indagan sobre procesos sociales; participación de los sujetos en la vida de la comunidad; estigmas, preconceptos y discriminaciones, así como realidades escondidas e invisibilizadas ${ }^{53}$.

De esta manera, la exégesis en perspectiva de mujeres puede, entre otras cosas, liberar los textos de una lectura que, tradicionalmente, ha sido androcéntrica; pero no sólo eso, trata, además, de hacer visibles los lenguajes no inclusivos; las figuras femeninas que pueblan los relatos bíblicos, y la descripción de su protagonismo en influencia en la comunidad; las imágenes femeninas de Dios; y también la de muchos otros protagonistas que quedan como escondidos detrás de las historias bíblicas ${ }^{54}$.

De hecho, de la riqueza de todas estas aportaciones de la perspectiva del trabajo exegético de las mujeres da buena cuenta la inclusión del acercamiento feminista en el conjunto de las herramientas de interpretación del texto sagrado presentadas en el documento de la Pontificia Comisión Bíblica La interpretación de la Biblia en la Iglesia, que reconoce que la participación activa de las mujeres en la investigación exegética ha permitido visibilizar la presencia y el papel de las mujeres en el mundo de la Biblia, y, así, ha brindado la posibilidad de plantear a los textos nuevas preguntas, a corregir ciertas interpretaciones y a fundamentar desde nuevas claves la Teología de la mujer.

\subsection{Dios}

V. Azcuy hace notar cómo «las cuestiones relativas al lenguaje teológico se entrelazan con los problemas hermenéuticos a la hora de revisar el modelo patriarcal en el hablar sobre Dios» ${ }^{55}$. Es decir, que encontramos en las mujeres que hacen Teología unos acentos propios no sólo en el cómo hablar de Dios, sino también a la hora de «decir algo de Dios», empezando por las imágenes de Dios.

Por ejemplo, las mujeres parece que tendemos a mostrar que la imagen de Dios trasciende el género, la dualidad masculino-femenino, desarrollando todo un lenguaje fuertemente simbólico, y recuperando y visibilizando imágenes de Dios que quizás se habían

\footnotetext{
52 Tânia Mara Vieira Sampaio, «Consideraciones para una hermenéutica de género del texto bíblico». Ribla 3, Vol. 37 (2000): 10.

${ }^{53}$ Tânia Mara Vieira Sampaio, «Consideraciones para una hermenéutica de género del texto bíblico», 8.

${ }^{54}$ Nuria Calduch, «El Éxito de La Exégesis Bíblica Femenina», L'Osservatore Romano, June 1, 2018, consultada en septiembre 17, 2019, http://www.osservatoreromano.va/es/news/el-exito-de-la-exegesis-biblicafemenina.

${ }^{55}$ Virginia Raquel Azcuy, «El lugar teológico de las mujeres»: 29.
} 


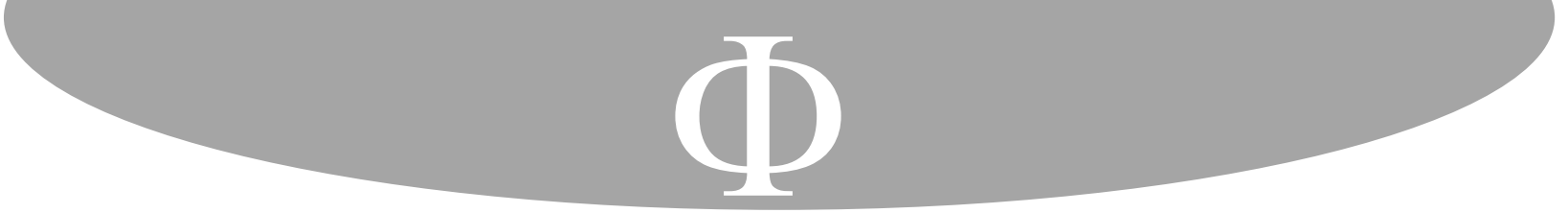

pasado por alto. Así se manifestaba alguno de los varones entrevistados en un artículo de la revista Mensaje de Chile: «Hay teólogas que saben argumentar desde dimensiones u orillas por donde no se asoma la mirada masculina. La dimensión materna de la Divinidad, por ejemplo, queda ampliada y resignificada» ${ }^{56}$.

Por esta razón, es habitual llevar las imágenes femeninas de Dios más allá de la lectura androcéntrica tradicional. Por ejemplo, las metáforas relativas a la maternidad cuando se aplican a Dios no se interpretan sólo en la perspectiva del cuidado, sino también de la consideración de un mundo en profundo riesgo, en los que lo herido, lo roto y lo vulnerable pueden sanar con la solidaridad y la reconciliación ${ }^{57}$

En este marco hay que colocar también los esfuerzos por utilizar títulos o figuras que engloben la totalidad del ser humano: entrañas maternas, dolores de parto, Sabiduría, Gloria, el Cristo de la vida y la gracia, todas ellos basadas en textos bíblicos ${ }^{58}$.

Tampoco es infrecuente que las mujeres que hacemos Teología manifestemos el sesgo patriarcal de la simbólica religiosa, y sus consecuencias en la comprensión de la organización de la comunidad, y de los roles que en ella desempeñan hombres y mujeres ${ }^{59}$.

Por último, las mujeres estamos tocadas en lo más profundo de nuestro ser por el Misterio del Dios de la vida, «sentimos el amor la intimidad y la interconexión y queremos expresar esta experiencia de modo diferente, con otros colores, otras manifestaciones y otra música»60, de modo que no es raro que hablemos teológicamente de Dios acentuando la dimensión mística de un Dios salvador y compasivo61:

Un Dios oculto, escondido, que se muestra en Jesús bajo una forma humilde, pobre y escarnecido, humillado y fracasado en la cruz, pero que nos aclara algo el misterio del ser humano, y que algo le aclara también a la mujer, pues ese Dios que se revela en Jesús es una prueba de la riqueza en la pobreza, de la impotencia humana, del amor en el abandono, de la plenitud en el vacío, de la vida en la muerte62.

\subsection{El ser humano}

\footnotetext{
${ }^{56}$ Paul Endre en Judith Schonsteiner y Claudia Leal, «Oídos de aquellas que tienen su propia voz», Mensaje 676 (2019): 32.

${ }^{57}$ Cf. Sue Monk Kidd, When the Heart Waits: Spiritual Direction for Life's Sacred Questions.

${ }^{58}$ Ver Carmen Bernabé, «Cuando Jesús dice mujer... Cuando la mujer dice Jesús», en Algunas mujeres nos han sobresaltado (Madrid: Claretianas, 1993), 155.

${ }^{59}$ Adriana Valerio, «Le mammelle di Giesù», en Sabina Caligiani, La voce delle donne. Pluralità e differenza nel cuore della Chiesa (Milano: Paoline, 2019), 9-22.

${ }^{60}$ Ana María Tepedino, «Gender and New (Re-newed) Images of the Divine», Voices from the Third World 24 (2001): 90 .

${ }^{61}$ María Clara Luchetti Bingemer, O Segredo Feminino do Mistério. Ensaios de Teología na ótica da mulher, 97.

${ }^{62}$ Felisa Elizondo, «Mujer», 128.
} 


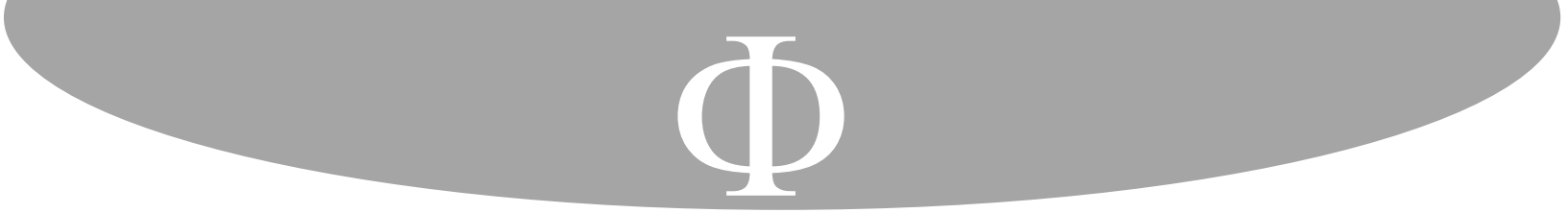

En todo caso, parece que la lucha de las mujeres por su autodeterminación puede servir de paradigma para favorecer a los colectivos con rasgos marcadamente diferentes que llaman a nuestras puertas ${ }^{67}$, y pueden incidir y postular una consideración de las relaciones entre las personas en clave de mutualidad y reciprocidad, que, sin negar el valor de la complementariedad, se muestra muy atenta a las relaciones asimétricas.

Desde esas mismas claves, es fácil comprender que se muchas veces sean mujeres las que reivindiquen, entre otras cosas, recuperar imágenes de la Iglesia más inclusivas: pueblo de Dios, misterio, sacramento; repensar la ministerialidad; y reformular la mariología a partir no sólo de María como madre, sino como discípula.

\subsection{Jesús y la Cristología}

La mexicana María Pilar Aquino ha escrito que en Cristo, en su persona y su praxis, las mujeres encontramos el modelo a partir del cual postular la liberación de cualquier discriminación $^{68 ;}$ quizás por esa razón' la Teología de mujeres, cuando trata la cristología, suele comenzar proponiendo reformular un desarrollo dogmático que conecta el Logos y la masculinidad del Jesús histórico ${ }^{69}$.

Esta perspectiva convierte a la cristología hecha por mujeres en un tratado fundamental y, a la vez, conflictivo

Para reinterpretar esa cristología que tiende a identificar lo masculino con lo divino, las mujeres teólogas rastrean las llamadas «cristologías alternativas» de las comunidades del tiempo que precede al Concilio de Calcedonia; no sólo eso, tratan de llegar hasta los orígenes del movimiento de Jesús, acentuando la Encarnación y mostrando la lógica de la kenosis como expresión de la preferencia de Dios por lo pequeño, lo débil, lo vulnerable ${ }^{70}$.

Así, por ejemplo, E. Schüssler Fiorenza ha insistido mucho en la comprensión del ministerio de Jesús como un discipulado de iguales que, además, posibilita la comprensión del Reino de Dios acentuando su desafío, al proponer una comunidad de iguales que se fundamenta en una comprensión de las relaciones basadas en el amor, la justicia, la reciprocidad $^{71}$.

En esa perspectiva, otras autoras destacan la perspectiva «provocativa» de la predicación de Jesús y de su estilo de vida opuesto al modelo de prepotencia de coloración patriarcal que se ejerce sobre las mujeres, pero también sobre los hombres marginados por

\footnotetext{
${ }^{67}$ Cettina Militello, «Women, Citizenship, Church», Journal of the European Society of Women in Theological Research 16 (2008): 25-36.

${ }^{68}$ María Pilar Aquino, Aportes para una teología desde la mujer: colaboraciones de teólogas latinoamericanas en la Conferencia Intercontinental de Mujeres Teólogas Del Tercer Mundo, celebrada del 1 al 6 de diciembre de 1986, en Oaxtepec (Madrid: Biblia y Fe, 1988).

${ }^{69}$ Simona Segoloni, Gesù, maschile singolare (Bologna: Edizioni Dehoniane Bologna, 2020).

${ }^{70}$ Carmiña Navia, «Jesús de Nazaret. Miradas Femeninas», Qol 30 (2002): 103-108.

${ }^{71}$ Ute Seibert, Espacios abiertos: caminos de la teología feminista (Santiago de Chile: Editorial Forja, 2010).
} 


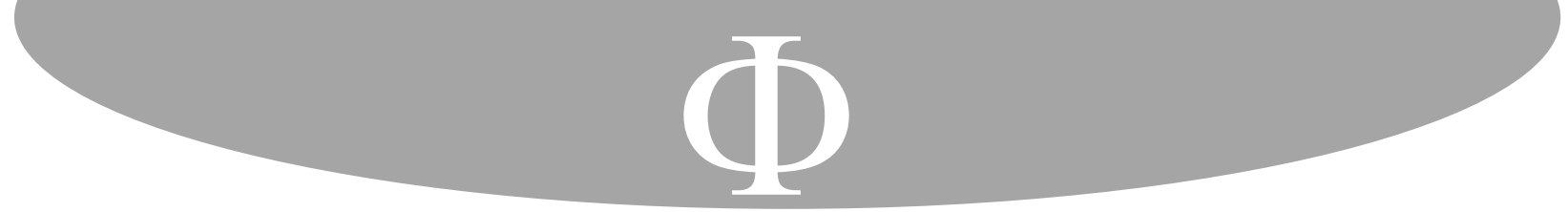

distintos motivos; no sólo eso, subrayan cómo ese estilo conllevó para él la condena y la muerte en cruz y, por esta razón:

Ellas han sido especialmente sensibles a los distintos «vicios» o «deformaciones» teológicas católicas que han emergido respecto de las interpretaciones de la cruz. Son las mujeres, principalmente, las que han alertado cómo la cruz se ha usado para justificar situaciones de abuso, maltrato y opresión. En este sentido, han afirmado que algunas lecturas patriarcales de la cruz han romantizado el sufrimiento ${ }^{72}$.

En definitiva, como hace notar M. T. Porcile, se trata de proponer una nueva cristología que acentúe mejor la dimensión inclusiva del mensaje de Jesús; una cristología que puede estar a la altura de estos tiempos de interculturalidad y multirreligiosidad: "Una cristología del tercer milenio que admitirá como compañeros de camino a todas las búsquedas llegadas desde el diálogo inter-religioso y, sobre todo, del diálogo judeo-cristiano. Será una cristología que tome en serio la Encarnación dentro de una cultura determinada y en un marco histórico concreto» ${ }^{73 .}$

\subsection{La Iglesia ${ }^{74}$}

La Teología sobre la Iglesia es, posiblemente, la que más aportaciones y reflexiones merece en la perspectiva de las mujeres, y en ella se dan cita, trabajando codo a codo teólogas de las distintas iglesias cristianas ${ }^{75}$.

Como hace notar Lucetta Scaraffia, a propósito del lugar que ocupamos las mujeres en la Iglesia, «no sólo nuestra presencia numérica es mayor, sino, lo que me parece más interesante, que las mujeres desarrollamos una responsabilidad fundamental en la transmisión de la fe cristiana (...) las mujeres son las que sacan adelante el cristianismo cotidiano» $^{76}$.

Una de las aportaciones propias de la eclesiología hecha por mujeres aboga por la recuperación de la consideración de la Iglesia como «casa»; espacio habitable, lugar de acogida y hospitalidad. De hecho, en relación con los ministerios, las mujeres reclamamos para nosotras lo mismo que para los varones laicos

\footnotetext{
${ }^{72}$ Camilo Barrionuevo en Schonsteiner y Leal, «Oídos de aquellas que tienen su propia voz»: 33.

${ }^{73}$ María Teresa Porcile, «Cristología en femenino»: 80-97.

${ }^{74}$ Virginia Raquel Azcuy, «La Iglesia que viven, sueñan y piensan las mujeres», presentación en Panel, en Semana de Teología 2001 (Buenos Aires: San Benito, 2002), 195.

75 Por ejemplo, el Foro ecuménico de mujeres cristianas, consultada en junio 1, 2020, http://www.efecw.net, que «imagina ser una comunidad cristiana viva de hermanas mediante la creación de un espacio abierto y seguro donde todas las mujeres, más allá de sus diferencias, tengan el poder de compartir su espiritualidad y experimentar la fe. El Foro se esfuerza por ser una voz reconocida de las mujeres cristianas en la iglesia y en la vida pública en Europa».

${ }^{76}$ Darío Menor, «Lucetta Scaraffia: "El problema es la discriminación de la mujer en la Iglesia, no el sacerdocio femenino"», Vida Nueva, 19 de octubre de 2012, consultada en diciembre 19, 2020, https://www.vidanuevadigital.com/2012/10/19/lucetta-scaraffia-el-problema-es-la-discriminacion-de-lamujer-en-la-iglesia-no-el-sacerdocio-femenino/.
} 


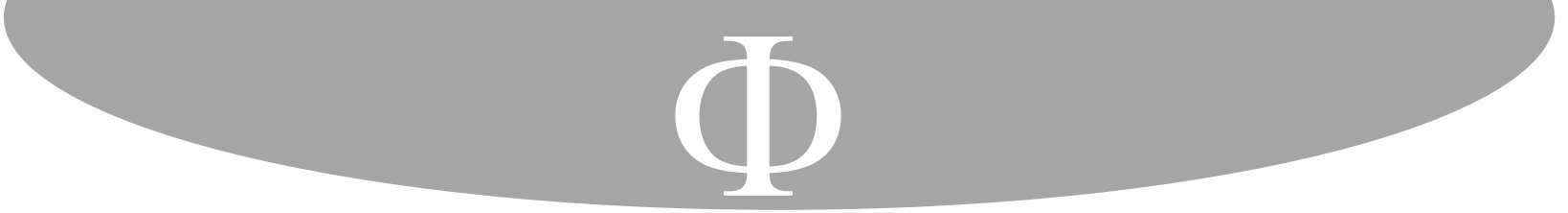

En este punto es bueno recordar la «mutualidad inclusiva y solidaria» 77 tan propia de las mujeres puede ayudar a reflexionar la Iglesia como «comunión» por caminos nuevos, por ejemplo, la «trama comunitaria» que está a la base de la concepción de la Iglesia.

Suscitar de nuevo esta imagen puede, para empezar, recuperar el éxodo de muchas mujeres; mujeres que piensan, y que están practicando el liderazgo de las comunidades ${ }^{78}$, a las que determinadas formas de ejercer el gobierno de tinte clericalista no les resultan ya aceptables.

Con esta perspectiva de fondo es fácil comprender que las mujeres teólogas reclamen una mayor insistencia en la dimensión de la sinodalidad, entendida esta como práctica de la convergencia y el diálogo, y que lo hagan partiendo de su propia experiencia creando redes y plataformas de trabajo conjunto ${ }^{79}$. En este punto, las mujeres que hacen eclesiología acentúan mucho la necesidad de experimentar modelos de liderazgo compartido. Así, postulan ejercicios más colegiales de los ministerios, en los que se acentúe más la comunidad a la que se sirve, que a quien la sirve; modelos que ayuden al gobierno a entender las posiciones de los miembros de la comunidad, y a dar voz a quien, naturalmente, no puede pronunciarla ${ }^{80}$.

De hecho, la Teología de la Iglesia hecha por mujeres plantea siempre la cuestión de los ministerios ${ }^{81} \mathrm{y}$, en no pocos casos, el acceso de la mujer al orden sacerdotal; una revisión de las consecuencias que tiene la imagen del sacerdote como varón al frente de la comunidad, un funcionamiento más colegiado y democrático; una reinterpretación de la misión de la Iglesia como «misión compartida».

¿Cómo se entiende la analogía del varón representando a Cristo cabeza de la comunidad, sin entender que el lugar de la mujer es sub-ordinado al del varón? Hay que encontrar un lugar, un espacio, una expresión a la igual dignidad de los sexos, tanto en el orden de la analogía, del símbolo, como en el orden de las cosas. Es un gran desafío para la Iglesia: encontrar un lugar para el carisma y servicio propios de la mujer, de manera que esto dé credibilidad a la igual dignidad de todos ${ }^{82}$.

\footnotetext{
77 Virginia Raquel Azcuy, «El lugar teológico de las mujeres»: 31.

${ }^{78}$ Ivone Gebara, «La Iglesia va a perder a las mujeres que piensan. Interview by Jesús Bastante», Religión Digital, 4 de octubre de 2018, consultada en diciembre 17, 2019, https://www.periodistadigital.com/cultura/religion/rel-mundo/20181001/ivone-gebara-iglesia-perder-mujerespiensan-noticia-689401776912/.

${ }^{79}$ Bernardita Zambrano y Sandra Arenas, «Hacia una orgánica eclesiástica inclusiva y simétrica», Mensaje 676 (2019): 30 .

${ }^{80}$ Lynn N. Rhodes y Kathlee M. Black, «Church Ministries and Worship», en Letty M. Russell y J. Shannon Clarkson, eds., Dictionary of Feminist Theologies (Louisville: Westminster John Knox Press, 1996).

${ }^{81}$ Estrella Moreno, «Nuevos rostros de la ministerialidad», Sal terrae 1257, Vol. 108 (2020): 631-644.

${ }^{82}$ Maria Josefina Llach, «Más lugar al espacio y más espacio s la mujer. Algunas notas para la renovación de la misión de la Iglesia en solidaridad y esperanza», en Sociedad Argentina de Teología SAT, ed., De La Esperanza a La Solidaridad. XX Semana Argentina de Teología (Buenos Aires: San Benito, 2002).
} 


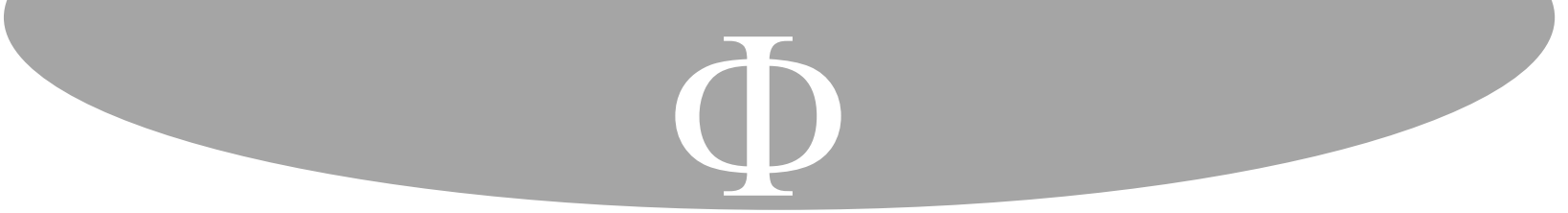

Así, en la Iglesia, las mujeres, «masivamente presentes pero ausentes de la orientación y dirección de la institución eclesial» ${ }^{83}$, no estamos pidiendo «participación»; no queremos que se hable sólo de nuestra «inserción» en la Iglesia, porque denota, una vez más, una visión masculina del gobierno focalizada en el reparto de poder $^{84}$. Las mujeres que estudian la eclesiología reclaman que el reconocimiento de la necesidad de contar con los criterios e intuiciones de las mujeres; de confiar a mujeres la organización y el gobierno cuando sea necesario para el buen funcionamiento de la comunidad, y estén suficientemente preparadas; que participen en las instancia de reflexión y decisión, principalmente en todo lo que tenga que ver con el sacerdocio común de los fieles ${ }^{85}$.

En este punto, las mujeres proponemos también una revisión de la Teología pastoral basada en el modelo clerical, que parece que sólo encuentra en la imagen de Jesús, buen pastor, el referente para pensar el cuidado y el acompañamiento del pueblo de Dios. Este modelo, de claro sabor bíblico, es, sin embargo, difícilmente reconducible en la perspectiva femenina porque comporta una lectura absolutamente diferente. De ahí que algunas autoras de Teología pastoral propongan, por ejemplo, una Teología pastoral a partir de la imagen del pueblo de Dios en éxodo hacia el Reino ${ }^{86}$.

En esta trama comunitaria, la liturgia desempeña una clave fundamental, y muchas mujeres, en la Teología académica o en el quehacer teológico de la praxis, hacen notar cómo determinadas precomprensiones del modo de celebrar, sólo contribuyen a reforzar la desigualdad porque acaban convirtiendo la liturgia en «cosa de hombres», y no en un asunto de la comunidad. Se hace necesario revisar no sólo el lenguaje y los símbolos, sino, especialmente, los ritos y su rigidez, para intentar darles una mayor flexibilidad que atienda a la diversidad de la Iglesia (una liturgia más vernácula, no sólo un uso de la lengua vernácula); que potencie la participación con el cuerpo y sus dimensiones; que evite cualquier lenguaje o gesto excluyente

Además, es bueno traer también la reflexión de muchas mujeres en torno a los modelos de santidad que la Iglesia propone a los fieles ${ }^{87}$, particularmente los modelos

\footnotetext{
${ }^{83}$ Carmelita de Freitas, «Desde el feminismo a las perspectivas de género», en AA.VV., Mujer y Vida Religiosa planteamientos y experiencias desde el feminismo y la perspectiva de género (Quito: Editorial Abya-Yala, 1998), 31.

${ }^{84}$ Silvia Martínez Cano, «Mujeres creyentes, culturas e iglesias. Reformas para comunidades católicas vivas y en acción», Journal of the European Society of Women in Theological Research 25 (2017): 143-165.

${ }^{85}$ Ana María Vega, «La participación de la mujer en la Iglesia, uno de los desafíos más importantes para la Iglesia en este s. XXI», consultada en junio 1, 2020, http://www.laici.va/content/dam/laici/documenti/donna/teologia/espanol/La\%20participaci\%C3\% B3n\%20de\%20la\%20mujer\%20en\%20la\%20Iglesia\%20AMVegaGutierrez.pdf.

${ }^{86}$ Riet Bons-Storm, «Dominant Practical Theology and the Feminist Perspectiva», en Hedwig Meyer-Wilmes, Lieve Troch, y Riet Bons-Storm, Des perspectives féministes en théologie pastorale (Leuven: Peeters Publishers, 1998).

${ }^{87}$ N.K. Watson, «What is the Church? Feminist Church History and Ecclesiology in Creative Dialogue», en European Society of Women in Theological Research: Jahrbuch der Europäischen Gesellschaft für die Theologische Forschung von Frauen 8 (2000): 79-99.
} 


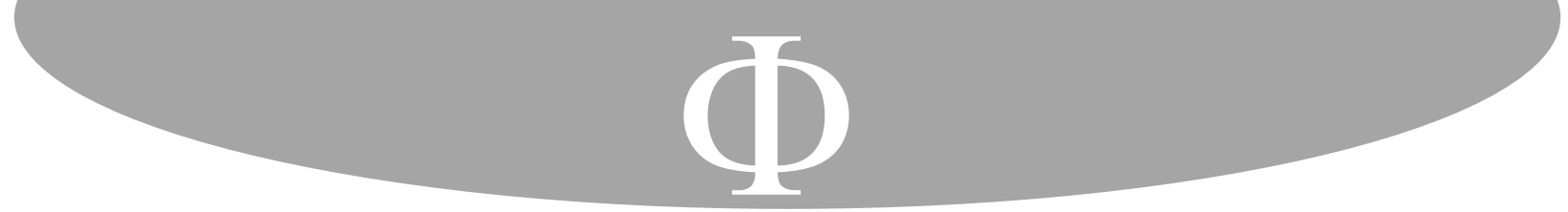

El hacer teológico de las mujeres no se define por los temas de las mujeres. (..) Tampoco es, forzosamente, Teología feminista. Es Teología hecha por mujeres, y esta Teología hecha por mujeres se diferencia de la Teología hecha por los hombres, dado que la Teología no es a-sexual, como tampoco es a-histórica, pues la Teología que parte de la realidad y vuelve a ella para transformarla es contextual e implica la perspectiva de género. Es, quizás, una forma diferente y alternativa de hacer Teología pero que no se ocupa únicamente de los intereses e interrogantes de las mujeres ni pretende competir o suplantar la Teología hecha por los hombres ${ }^{96}$.

Con todo, como afirma Nuria Calduch-Benages, todavía hoy tenemos «la necesidad de promover, sin infravalorar nunca valores como la maternidad o la virginidad, los dones intelectuales, espirituales y pastorales que las mujeres pueden ofrecer a la Iglesia» ${ }^{97}$.

Pero, en todo caso, me parece importante destacar como aporte que han hecho las mujeres, la ampliación de los escenarios eclesiales en los que desarrollar el oficio de la Teología trazando nuevas geografías del quehacer teológico y haciendo, como ya apuntamos, que la Teología se colara en todas las capas de la Iglesia.

Esta expansión del territorio de la Teología puede ayudar, además, a «aligerar las estructuras» de los escenarios académicos tradicionales:

Es indispensable dotarse de estructuras ligeras y flexibles, que manifiesten la prioridad dada a la acogida y al diálogo, al trabajo inter- y trans- disciplinar y en red. Los estatutos, la organización interna, el método de enseñanza, el plan de estudios, deberían reflejar la fisonomía de la Iglesia «en salida». Todo debe orientarse en los horarios y en los modos que se favorezca lo más posible la participación de aquellos que desean estudiar Teología: además de los seminaristas y los religiosos, también los laicos y las mujeres, tanto laicas como religiosas ${ }^{98}$.

Por otra parte, me parece que también es posible perfilar unas aportaciones singulares de carácter epistemológico que tienen que ver con el «ensanchamiento de la racionalidad», el reconocimiento del valor de la experiencia en la reflexión teológica, y la contribución de la narración a la formulación del discurso teológico.

Y, por último, resulta posible identificar cuál sea el lugar teológico de las mujeres, «ser mujer y tener experiencia de serlo», un lugar en el que los cuerpos de las mujeres, cuerpos, receptores y dadores de vida constituyen, conciban o no, un espacio totalmente original:

\footnotetext{
${ }^{96}$ Isabel Corpas de Posada, «Mujeres teólogas: ¿cuál es nuestra identidad y nuestro aporte al quehacer teológico?», Franciscanum 151 (2009): 66-67.

${ }^{97}$ Patricia Navas, «La Iglesia en busca de la feminidad». Aleteia.org | Español - valores con alma para vivir feliz, 4 de diciembre de 2013, consultada en diciembre 17, 2020, https://es.aleteia.org/2013/12/04/la-iglesia-enbusca-de-la-feminidad/.

${ }^{98}$ Francisco, Visita del Santo Padre Francisco a Nápoles con motivo del congreso «La teología después de la Veritatis Gaudium en el contexto del mediterráneo».
} 


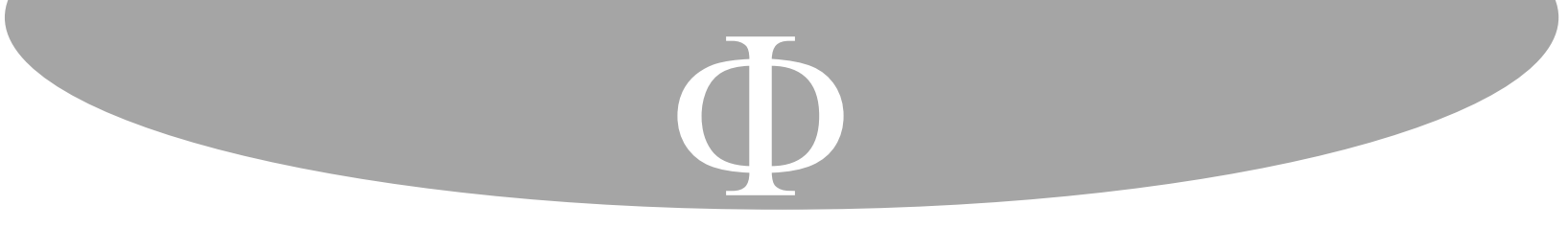

Scannone, Juan Carlos. «Cuestiones actuales de epistemología teológica. Apuntes de la Teología de la liberación». Stromata 45 (1990): 293-336.

Schönsteiner, Judith. «Si la pobreza tiene rostro de mujer, la teología no puede no tenerlo». Consultada en junio 8, 2020, https://territorioabierto.jesuitas.cl/la-pobreza-rostromujer-la-teologia-no-puede-no-tenerlo/.

Schonsteiner, Judith y Leal, Claudia. «Oídos de aquellas que tienen su propia voz». Mensaje 676 (2019): 32-35.

Segoloni, Simona. Gesù, maschile singolare. Bologna: Edizioni Dehoniane Bologna, 2020.

Seibert, Ute. Espacios abiertos: caminos de la teología feminista. Santiago de Chile: Editorial Forja, 2010.

Silva, Sergio. «La Exhortación Apostólica del papa Francisco como desafío a los teólogos». Teología y vida 3 (2014): 549-569.

Sobrino, Jon. Resurrección de la verdadera Iglesia. Los pobres, lugar teológico de la eclesiología. Santander: Sal Terrae, 1981.

Sociedad Argentina de Teología, ed. De la esperanza a la solidaridad. XX semana argentina de teología. Buenos Aires: San Benito, 2002.

Tamayo, Juan José y Bosch, Juan. Panorama de la teología latinoamericana: cuando vida y pensamiento son inseparables. 2nd ed. Estella: Editorial Verbo Divino, 2001.

Támez, Elsa. «Descubriendo Rostros Distintos de Dios». Redes Cristianas. Consultada en septiembre

15 ,

2020

http://www.redcristianaradical.org/uploads/3/4/5/3/34530228/descubriendo_rostros_ distintos_de_dios_e_tamez.pdf.

Támez, Elsa. «La vida de las mujeres como texto sagrado». Concilium 276 (1998): 419-428.

Támez, Elsa. Las Mujeres toman la palabra: en diálogo con teólogos de la liberación hablan sobre la mujer. San José: Editorial Departamento Ecuménico de Investigaciones, 1989.

Támez, Elsa. Teólogos de la liberación hablan sobre la mujer. San José: Editorial Departamento Ecuménico de Investigaciones, 1986.

Tepedino, Ana María. «Gender and New (Re-newed) Images of the Divine». Voices from the Third World 24 (2001): 84-96.

Teresa de Jesús. Obras completas. Burgos: Monte Carmelo, 1998.

Torre, Francisco Javier De la (ed.). Mujer, mujeres y bioética. Madrid: Universidad Pontificia Comillas, 2010.

Varo, Antonio. «María Dolores Aleixandre, teóloga: hasta ahora, se nos ha estado hablando de Dios con un solo altavoz». Diario de Córdoba, 17 de noviembre de 2007. Consultada en junio 1, 2020, https://www.diariocordoba.com/cordobaciudad/2007/11/17/maria-dolores-aleixandre-teologa-ahora-38355432.html.

Vega, Ana María. «La participación de la mujer en la Iglesia, uno de los desafíos más importantes para la Iglesia en este s. XXI». Consultada en junio 1, 2020, http://www.laici.va/content/dam/laici/documenti/donna/teologia/espanol/La\%20part icipaci\%C3\%B3n\%20de\%20la\%20mujer\%20en\%201a\%20Iglesia\%20AMVegaGuti errez.pdf.

Vélez Caro, Olga Consuelo. «Teologías y Métodos». Theologica Xaveriana 153 (2005): 2952.

Vélez Caro, Olga Consuelo. «Teología de la mujer, feminismo y género». Theologica 


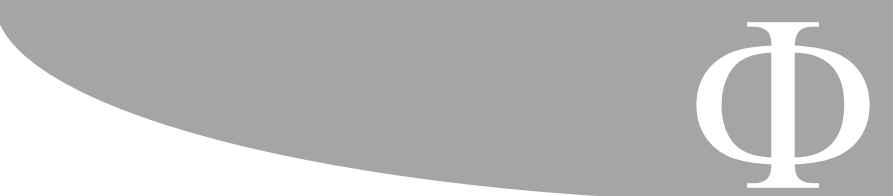

Xaveriana 140 (2001): 545-564.

Vieira Sampaio, Tânia Mara. «Consideraciones para una hermenéutica de género del texto bíblico». Ribla 3, Vol. 37 (2000): 7-14.

Watson, N.K. «What is the Church? Feminist Church History and Ecclesiology in Creative Dialogue». En European Society of Women in Theological Research: Jahrbuch der Europäischen Gesellschaft für die Theologische Forschung von Frauen 8 (2000): 7999.

Zambrano, Bernardita y Arenas, Sandra. «Hacia una orgánica eclesiástica inclusiva y simetrica». Mensaje 676 (2019): 28-31.

Zarazaga, Gonzalo J. «La religiosidad popular latinoamericana como "lugar teológico"». Stromata 55 (1999), 3-18.

Enviado: 18 de junio de 2020 Aceptado: 1 de septiembre de 2020 